\title{
Silicon nanostructures produced by laser direct etching
}

\author{
Müllenborn, Matthias; Dirac, Paul Andreas Holger; Petersen, Jon Wulff
}

Published in:

Applied Physics Letters

Link to article, DOI:

10.1063/1.114257

Publication date:

1995

\section{Document Version}

Publisher's PDF, also known as Version of record

Link back to DTU Orbit

Citation (APA):

Müllenborn, M., Dirac, P. A. H., \& Petersen, J. W. (1995). Silicon nanostructures produced by laser direct etching. Applied Physics Letters, 66(22), 3001-3003. https://doi.org/10.1063/1.114257

\section{General rights}

Copyright and moral rights for the publications made accessible in the public portal are retained by the authors and/or other copyright owners and it is a condition of accessing publications that users recognise and abide by the legal requirements associated with these rights.

- Users may download and print one copy of any publication from the public portal for the purpose of private study or research.

- You may not further distribute the material or use it for any profit-making activity or commercial gain

- You may freely distribute the URL identifying the publication in the public portal

If you believe that this document breaches copyright please contact us providing details, and we will remove access to the work immediately and investigate your claim 


\title{
Silicon nanostructures produced by laser direct etching
}

\author{
M. Müllenborn, ${ }^{\text {a) }}$ H. Dirac, and J. W. Petersen \\ Mikroelektronik Centret (MIC), Danmarks Tekniske Universitet, Lyngby, Denmark
}

(Received 20 January 1995; accepted for publication 10 March 1995)

\begin{abstract}
A laser direct-write process has been applied to structure silicon on a nanometer scale. In this process, a silicon substrate, placed in a chlorine ambience, is locally heated above its melting point by a continuous-wave laser and translated by high-resolution direct-current motor stages. Only the molten silicon reacts spontaneously with the molecular chlorine, resulting in trenches with the width of the laser-generated melt. Trenches have been etched with a width of less than $70 \mathrm{~nm}$. To explain the functional dependence of the melt size on absorbed power, the calculations based on a two-phase steady state heat model are presented, taking the temperature-dependent thermal conductivities and optical parameters into account. (C) 1995 American Institute of Physics.
\end{abstract}

Writing structures directly into silicon is interesting for applications, in which a high resolution and a high degree of flexibility are wanted. Many direct-write processes have the disadvantage of long processing times and limited process ranges, if they operate at high resolution. Silicon can be etched directly with volumetric removal rates of more than $10^{4} \mu \mathrm{m}^{3} / \mathrm{s}$ at submicrometer resolution by producing a local melt, which is reacted with molecular chlorine gas. ${ }^{1}$ This etch process is highly selective and isotropic because only molten regions are being removed. The crystalline silicon reacts negligibly with the molecular chlorine even at elevated temperatures. ${ }^{2}$

Using a tightly focused laser beam to generate the silicon melt, its size can be reduced into the nanometer regime by decreasing the total absorbed power. Structures can be etched with features in the range of tens of nanometers by translation of the substrate, which supports optimum beam quality and large access range.

Our experimental setup ${ }^{3}$ consists of a continuous-wave argon ion laser with an UV option, high quality UV optics for beam expansion, an acousto-optic modulator for intensity modulation, and a reflective objective with a numerical aperture of 0.5 for focusing. The objective, which is adjusted for infinite conjugate ratio and a $1 \mathrm{~mm}$ thick quartz window, generates a diffraction-limited spot with a diameter of about $600 \mathrm{~nm}$ for $488 \mathrm{~nm}$ light. Instead of deflecting the beam, a lightweight process chamber is translated by $X / Y$ highresolution direct-current motor stages. Internal encoders assure accurate positioning and scanning with a bidirectional repeatability of $25 \mathrm{~nm}$ over a travel range of $100 \mathrm{~mm}$ using scan speeds up to $100 \mathrm{~mm} / \mathrm{s}$. Position information is provided through a direct axis interface and is used for on-thefly beam switching. The focus is displaced by an equivalent $Z$ stage. The interference pattern generated by front and back side reflection of a quartz plate is used to optimize the collimation of the incident and reflected beam, ensuring an optimum focus. All optical and stage components are mounted on vibration-damped tables and holders. Chlorine and nitrogen are led through flexible Teflon tubes and regulated by a mass flow controller/valve system. A CCD camera monitors the etch process in real time through the focusing objective.

${ }^{a)}$ Electronic mail: matthias@mic.dtu.dk
The silicon substrates used for etching are untreated wafers with the native oxide unremoved. They are loaded into the process chamber which is purged by dry nitrogen. During the etching process, the chamber is filled with about 400 mbar of molecular chlorine without buffer gas. Most of the experiments are carried out at a wavelength of $488 \mathrm{~nm}$ to avoid absorption in the chlorine gas. At the $351 \mathrm{~nm}$ Ar line, chlorine molecules absorb and dissociate efficiently, which causes unwanted spontaneous etching of the surface in the high pressure regime. Above a threshold power density, corresponding to an incident total power of about $250 \mathrm{~mW}$, melting occurs in a small fraction of the spot, indicated by a strong reflection due to the higher reflectivity of silicon above the melting point.

Using $488 \mathrm{~nm}$ light, single trenches have been etched with a width of less than $70 \mathrm{~nm}$ and a corresponding depth of up to $10 \mathrm{~nm}$ (Fig. 1). The radius of curvature between sidewall and surface is less than $20 \mathrm{~nm}$ for these trenches, which is the radius of the tip used for the atomic force microscopy (AFM) images.

In general, process parameters follow the trends found for larger melt sizes. ${ }^{1}$ The reaction rate is not transportlimited even at higher pressures, because of the small process

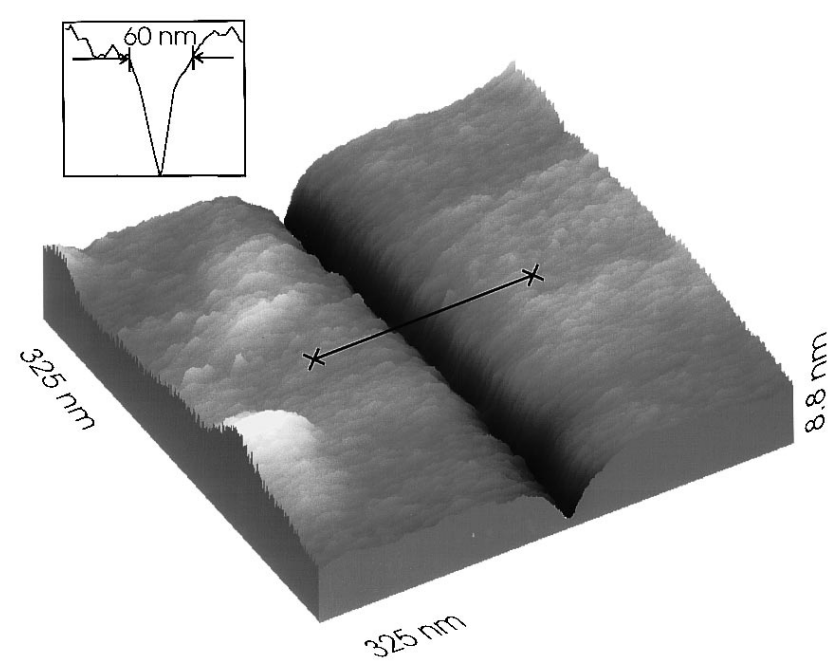

FIG. 1. AFM image of a laser-etched trench in bulk silicon, which is about $60 \mathrm{~nm}$ wide and $6 \mathrm{~nm}$ deep. The insert displays the cross-sectional scan marked in the AFM image. 


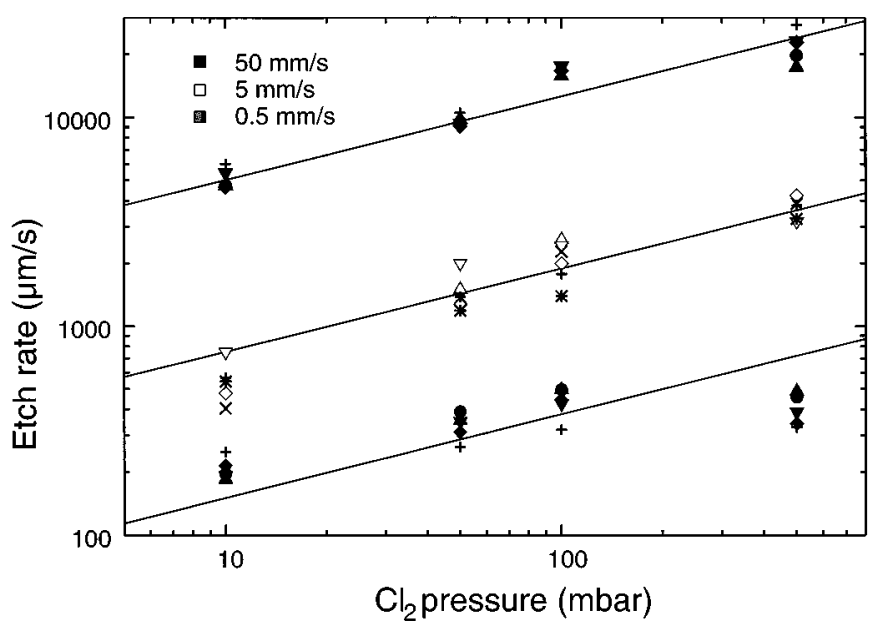

FIG. 2. Experimentally determined etch rate as a function of chlorine pressure and scan speed for reaction zones smaller than $500 \mathrm{~nm}$. The etch rate has been calculated as trench depth over exposure time, which is trench width over scan speed. The etch rate increases with chlorine pressure with a power of 0.4 (lines) and decreases with exposure time, indicated by higher etch rates for higher scan speeds.

area. The trench depth scales sublinearly with chlorine pressure and exposure time (Fig. 2), the width is mainly a function of absorbed power. Experimentally, the trench width is limited by vibrations and intensity fluctuations. Vibrations such as acoustic noise are picked up by the positioning system. Fluctuations in absorbed power can be due to instabilities of the optical system or due to surface inhomogeneities. Interference effects at the surface structures, such as trenches or scratches, are observed for linearly polarized light and attributed to the well-known "ripple" phenomenon. ${ }^{4,5}$ For a polarization perpendicular to the scan direction, parallel trenches with a spacing of about one wavelength are obtained for high laser powers. Because our spot size is of the order of the laser wavelength, we can adjust the total power that only one interference maximum has the necessary power for melting. This effect can actually be used to enhance the resolution.

Since trench features such as the radius between sidewall and surface and the surface roughness in the trench are on an even smaller scale, it is assumed that the melt size is limited by technical restrictions and that it can be reduced further by decreasing the spot size, damping vibrations, surface cleaning, and stabilization of the laser output. Some of these nanoscale features can be applied by accurate positioning of trenches. $40 \mathrm{~nm}$ thin walls have been etched by etching trenches with close spacing (Fig. 3). An array of sharp tips has been produced by scanning in $X$ and $Y$ direction. This close spacing of etched structures requires a consideration of the lateral heat confinement. Trenches broaden significantly in a dense configuration.

In order to determine the minimum possible size of a melt generated by a focused laser beam, we apply a solution of the heat equation and take the temperature-dependent optical and thermal parameters of the two phases into account. Optical and thermal parameters of silicon change profoundly at higher temperatures and at the phase transition. ${ }^{6,7}$ The sudden increase of reflectivity at the melting point is the most

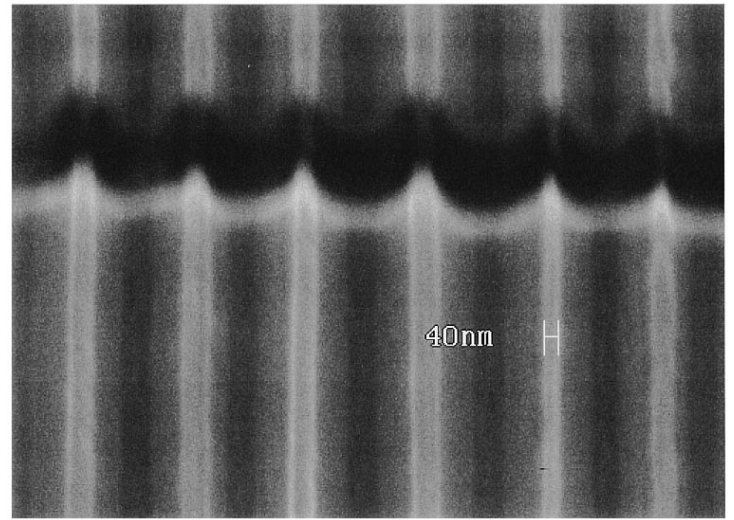

FIG. 3. SEM picture of laser-etched trenches with a width of $250 \mathrm{~nm}$ and a spacing of $300 \mathrm{~nm}$. Thin walls are left with a width of $50 \mathrm{~nm}$ at the surface and a height of about $100 \mathrm{~nm}$.

critical condition because it can inhibit the formation of a small melt. If one assumes steady state conditions, the heat equation can be written as

$$
\nabla[\kappa(T) \nabla T]=Q .
$$

$\kappa(T)$ is the temperature-dependent thermal conductivity, $T$ the temperature, and $Q$ the generation term. The temperature-dependent thermal conductivity is eliminated by introducing a linearized temperature ${ }^{8,9}$

$$
\theta(T)=\theta\left(T_{0}\right)+\int_{T_{0}}^{T} \frac{\kappa\left(T^{\prime}\right)}{\kappa\left(T_{0}\right)} d T^{\prime} .
$$

$T_{0}$ is the substrate temperature far away from the generation area. This linearization is most interesting for cases in which the back transformation can be done analytically. A fit to experimental data reveals $\kappa(T) \sim T^{-1}$ below the melting point $T_{m} \cdot{ }^{8}$ Above the melting point, $T(\theta)$ can be derived by inverting Eq. (2), assuming a constant thermal conductivity $\kappa\left(T_{m}\right)$;

$$
\begin{aligned}
& T(\theta)=T_{k}+\left(T_{0}-T_{k}\right) \exp \left[\theta /\left(T_{0}-T_{k}\right)\right]\left(\theta \leqslant \theta\left(T_{m}\right)\right), \\
& T(\theta)=T_{m}+\kappa\left(T_{0}\right) / \kappa\left(T_{m}\right)\left[\theta-\theta\left(T_{m}\right)\right]\left(\theta>\theta\left(T_{m}\right)\right) .
\end{aligned}
$$

The experimental thermal conductivity can be fit with $T_{k}=99 \mathrm{~K}$. After the problem has been reduced to Poisson's equation, $\nabla^{2} \theta=Q / \kappa\left(T_{0}\right)$, the generation term has to be simplified. Since the absorption coefficient of silicon is high at the melting temperature, the generation can be restricted to the surface at $z=0$. The solution for a Gaussian beam profile is then given $b^{8}$

$$
\begin{aligned}
\theta= & \sqrt{2 / \pi^{3}} \frac{P(1-R)}{\kappa\left(T_{0}\right) \omega_{0}} \int_{0}^{\infty}\left(1+u^{2}\right)^{-1} \\
& \times \exp \left[-2 / \omega_{0}^{2}\left(\frac{x^{2}+y^{2}}{1+u^{2}}+\frac{z^{2}}{u^{2}}\right)\right] d u .
\end{aligned}
$$

$P$ is the total incident power and $\omega_{0}$ the laser spot radius. However, the effect of a temperature-dependent reflectivity has to be included iteratively. The functional dependence of the reflectivity on temperature below the melting point has been extracted from experiments. ${ }^{8}$ Above the melting point, 


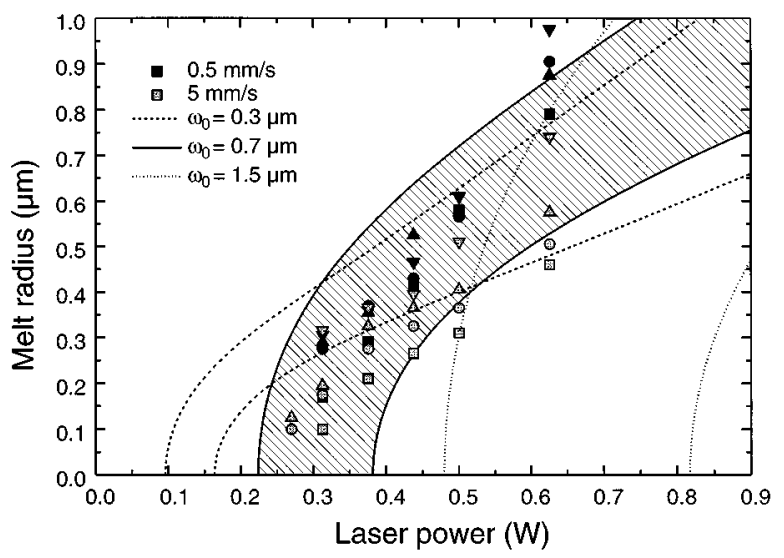

FIG. 4. Radius of a laser-induced silicon melt as a function of incident power. For a given spot radius $\omega_{0}$, minimum and maximum melt radii can be calculated as a function of power by an analytical model (lines). Trench widths as determined from cross-sectional SEM pictures (symbols) for two different scan speeds lie in the region of possible melt sizes of a $0.7 \mu \mathrm{m}$ spot (hatched region).

the reflectivity is determined by the metallic behavior of liquid silicon. It follows the curve predicted for an ideal electron gas; ${ }^{6,10}$

$$
\begin{aligned}
R(T)= & 0.324+4.0 \times 10^{-5} T \\
& (T \leqslant 1000 \mathrm{~K}), \\
R(T)= & 0.584-4.8 \times 10^{-4} T+2.6 \times 10^{-7} T^{2} \\
& (1000 \mathrm{~K}<T \leqslant 1685 \mathrm{~K}), \\
R(T)= & 0.542+3.1 \times 10^{-4} T-1.3 \times 10^{-7} T^{2} \\
& (T>1685 \mathrm{~K}) .
\end{aligned}
$$

The discontinuous increase of reflectivity at the melting point generates an instable region at the boundary of the melt. A slight change in temperature results in a large variation of absorbed power. Since the temperature in this region is very close to the melting temperature, the actual extent of the melt is strongly influenced by local disturbances and second-order contributions to the energy balance. The impact of latent heat and heat of formation on the local melting process can only be assessed by a full time-dependent numerical simulation. However, the minimum and maximum possible extent of the melt is obtained by using the reflectivity of liquid and solid silicon at the melting temperature, respectively. The melt size as a function of laser power and spot size can be determined by inverting the analytical relation (4). The minimum and maximum melt sizes and their difference decrease monotonously with laser power (Fig. 4), showing no absolute minimum according to the analytical model. Experiments, in which the width of laser-etched trenches was determined by cross-sectional scanning electron micrographs (SEM), confirm the relation between melt size and laser power (Fig. 4). In the best fit, which is obtained for a spot radius of $0.7 \mu \mathrm{m}$, most trench widths fall into the region between minimum and maximum calculated melt extents.

In conclusion, trenches with a width of less than $100 \mathrm{~nm}$ have been etched directly into silicon by a laser direct-write process. The resolution of this process is determined by the extent of a local melt, which can be reduced to a minimum by reducing the total absorbed power. Although even smaller melt sizes are predicted by a heat model, the resolution is experimentally limited by intensity fluctuations and vibrations.

${ }^{1}$ T. M. Bloomstein and D. J. Ehrlich, Appl. Phys. Lett. 61, 708 (1992).

${ }^{2}$ G. V. Treyz, R. Beach, and R. M. Osgood, Jr., J. Vac. Sci. Technol. B 6, 37 (1988).

${ }^{3}$ M. Müllenborn, H. Dirac, and J. W. Petersen, Appl. Surf. Sci. 86, 568 (1995).

${ }^{4}$ Z. Guosheng, P. M. Fauchet, and A. E. Siegman, Phys. Rev. B 26, 5366 (1982).

${ }^{5}$ J. E. Sipe, J. F. Young, J. S. Preston, and H. M. van Driel, Phys. Rev. B 27, 1141 (1983)

${ }^{6}$ M. O. Lampert, J. M. Koebel, and P. Siffert, J. Appl. Phys. 52, 4975 (1981).

${ }^{7}$ K. Yamamoto, T. Abe, and S. Takasu, Jpn. J. Appl. Phys. 30, 2423 (1991); S. Kimura (unpublished).

${ }^{8}$ D. Bäuerle, Chemical Processing with Lasers (Springer, Berlin, 1986)

${ }^{9}$ M. Lax, Appl. Phys. Lett. 33, 786 (1978).

${ }^{10}$ C. I. H. Ashby and J. Y. Tsao, in Laser Microfabrication, edited by D. J. Ehrlich and J. Y. Tsao (Academic, Boston, 1989), p. 231. 